\title{
The use of antibiotics in the university hospitals of Conakry: evaluation of the consumption and the analysis of determinants
}

\author{
Mory Keita ${ }^{1}$, Falaye Traore ${ }^{1}$, Mohamed Elmahady Camara ${ }^{2}$, Ansoumane Yassima Camara ${ }^{3}$, \\ Sah Dimio Sandouno ${ }^{4}$, Thierry Van Hees ${ }^{5}$
}

\author{
${ }^{1}$ National Institute of Public Health, Republic of Guinea \\ ${ }^{2}$ Faculty of Medicine, Pharmacy, and Odonto-Stomatology of the University GAN of Conakry Guinea \\ ${ }^{3}$ Agency of Public Health, Canada \\ ${ }^{4}$ Department of Public Health, Republic of Guinea \\ ${ }^{5}$ Department of Clinical Pharmacy, University of Liege, Belgium
}

Received: 13 April 2016

Accepted: 07 May 2016

\section{*Correspondence:}

Dr. Mohamed Elmahady Camara,

E-mail: elmahady7@gmail.com

Copyright: ( ) the author(s), publisher and licensee Medip Academy. This is an open-access article distributed under the terms of the Creative Commons Attribution Non-Commercial License, which permits unrestricted non-commercial use, distribution, and reproduction in any medium, provided the original work is properly cited.

\begin{abstract}
Background: The main objectives of this study were to evaluate the use of antibiotics; assess the knowledge and perception of prescribers regarding the use of antibiotics; to describe the policy on the use of antibiotics and to identify factors associated with high antibiotic consumption at the University Hospital of Conakry.

Methods: This study has two components: a retrospective study covering three months' consumption of antibiotics (From January 2013 to March 2013), and a cross-sectional study on both the knowledge and perception of prescribers concerning the use of antibiotics and the policies on their proper use.

Results: Of a total of 1,199 cases examined at the University Hospital of Conakry, 953 patients received at least one antibiotic about $79.5 \%$ of the total cases. The total amount consumed was 55.3 DDD / 100 BD. The class of the Extended-spectrum penicillin's was widely the most used at 22.9 DDD / $100 \mathrm{BD}$. The median knowledge score of prescribers; valued at a total of 8 , was equal to 5. The Composite Index for proper use of Antibiotic (CIATB) was $2.25 / 20$. Determinants or factors associated with the large use of antibiotics were the hospital site, the ward and the average length of stay.

Conclusion: Based on the results of our study, it appears that lot antibiotics are largely consumed at the University Hospital of Conakry; and that consumption are influenced by the hospital site, the ward and the length of stay. This study reveals also the absence of any policy of the rational use of antibiotics. Therefore, the study illustrates the need for the implementation of an antimicrobial stewardship action.
\end{abstract}

Keywords: Antibiotics, Consumption, Determinants, Conakry, Penicillin's, Hospital

\section{INTRODUCTION}

The inappropriate use of drugs is a major concern of public health programs. Globally, over $50 \%$ of all medicines are prescribed, distributed or sold inappropriately and more than $50 \%$ of countries do not implement the basic policies to promote the rational use of medicines. ${ }^{1}$ In developing countries, less than $40 \%$ of patients in the public sector and less than $30 \%$ in the private sector are treated according to clinical guidelines. ${ }^{2}$

Among the current problems related to irrational drug use appears the overuse of antibiotics. ${ }^{2}$ Indeed, antibiotics are among the drugs most frequently prescribed to the hospitalized patients. Studies indicate that nearly a third of all of the hospitalized patients receive antimicrobial 
therapy. ${ }^{3,4}$ Moreover, antimicrobial agents are among the most costly drug expenditure categories in hospitals, which account for about $20-50 \%$ of total drug spending. ${ }^{5}$

Furthermore, the amount of antibiotics used in hospitals and in the community is in correlation with the occurrence of antimicrobial resistance. ${ }^{6,7,8}$ The consequence of this increase in the antibiotic resistance in the practice of the hospital is the increase of the morbidity rate, the mortality rate and the cost of the hospitalization. ${ }^{9}$

If the antibiotics have been a revolution in the treatment of infections and the improvement of public health in the twentieth century, the gains from the point of view of reducing the morbidity and the mortality; however, may be lost during the twenty-first century with the emergence of multidrug-resistant bacteria. This is a threat that goes beyond the hospital settings, but particularly affects hospitals. $^{10}$ The need to improve the prescription of antibiotics in hospitals worldwide is urgent. But, to achieve the improvements in the rational use of antibiotics, we must first understand the causes; for example, the determinants of appropriate and inappropriate use. ${ }^{11}$

However, before studying the determinants, it is necessary to measure the consumption of antibiotics in an objective way. For this purpose; the analyze of drug consumption by defined daily dose (DDD), developed and updated at regular intervals by the WHO, can be used and this process can provide an opportunity to make a fair comparison between hospitals and countries..$^{12,13}$

Measuring the consumption, according to the WHO standard in teaching hospitals has been the subject of several publications in developed countries. ${ }^{2,12,14}$ Despite the frequency of their use, the subject of antibiotics has not been much addressed in African hospitals. The few published studies on antibiotics are often limited to wards or knowledge, attitudes and practices of physicians. ${ }^{15,16}$ But to date, very few have focused on the assessment of consumption of antibiotics in university hospitals and the factors associated with that consumption.

The objectives of this study were to evaluate the use of antibiotics, assess the knowledge and perception of antibiotic prescribers, describe the policy on the use of antibiotics and identify the factors associated with a high consumption of antibiotics at the University Hospital of Conakry.

\section{METHODS}

Our study was conducted in the University hospital of Conakry, located in the Republic of Guinea. It consists of two tertiary level hospitals, the National Hospital of IGNACE DEEN and National Hospital of DONKA, with a total capacity of 981 beds (466 beds and 515 beds respectively). The following hospitalization wards were particularly studied: medicine, surgery, pediatrics and maternity. This study has two components: a retrospective study of antibiotics consumption and a cross-sectional study of the knowledge and perception of antibiotic prescribers, and the policy on the use of antibiotics.

For the retrospective study, we analyzed the antibiotics consumption of all patients admitted from January 2013 to March 2013 to the wards of Medicine, Surgery, Pediatrics and Maternity. The unit of measure was DDD /100 BD. ${ }^{13}$ Antibiotics included were the systemic ones. The consumption of Imidazole per OS (classified P01) and Rifampicin were also noted. Anti-tuberculosis drugs, antiviral and antiparasitic drugs were excluded. Antibiotics used to target digestive decontamination were also excluded.

The cross-sectional study was focused on the knowledge and perception of antibiotics prescribers firstly, and on the other hand, the policies on the proper use of antibiotics. The sample consisted of all prescribers (medical internists, general practitioners, specialists.) of the above mentioned services; but also, two hospital pharmacy directors regarding the political aspect in the use of the antibiotics. The knowledge was assessed by an adapted questionnaire with a total of eight questions, divided into three case presentations and five questions on the properties of antibiotics. ${ }^{16}$ The policy was assessed by the Composite Index for proper use of Antibiotics (CIATB) which consists of three chapters: Organization (O: 4 points), Resources (R: 8) and actions (A: 8 points). ${ }^{17}$

\section{Data registration and statistical analysis}

Data were entered and analyzed using Excel and STATISTICA Version 10. We made descriptive analysis and inferential statistics. The means of two populations were compared using a $\mathrm{T}$ test for independent samples when the distribution is normal or the Mann-Whitney test when it is not. For the comparison of several populations, we used one-way analysis of variance or the KruskalWallis test. Normality was verified using the W test of SHAPIRO-WILK. As for proportions, they were compared using a Chi-square test. In addition, multiple regression analysis was performed to identify the factors associated with the antibiotics consumption in patients. For all analyses, the results were considered significant with $\alpha=5 \%(\mathrm{p}<0.05)$.

\section{RESULTS}

\section{Consumption description}

1199 patients were admitted during the studied period (January 2013 to March 2013). 953 patients received at least one antibiotic with $79.5 \%$ utilization rate. This rate ranged from $77.6 \%$ to DONKA national hospital to $81.8 \%$ in IGNACE DEEN National Hospital. 
Total consumption rose to 55.3 DDD / 100 BD. This suggests that $55.3 \%$ of hospitalized patients received a daily antibiotic. The consumption varied between the two national hospitals, 61.6 DDD / $100 \mathrm{BD}$ at IGNACE
DEEN and 49.7 DDD / $100 \mathrm{BD}$ at DONKA with significant difference $(\mathrm{p}<0.001)$. Consumption was larger in maternity than in surgery wards (Table 1$)$.

Table 1: Total consumption of antibiotic at the Conakry university hospital.

\begin{tabular}{|lllllll|}
\hline Wards & University Hospital & \multicolumn{2}{l}{ Ignace Deen Hospital } & Donka Hospital & \\
& DDD & DDD/100BD & DDD & DDD/100BD & DDD & DDD/100BD \\
\hline Medicine & 1151.3 & 36.1 & 527.2 & 42.1 & 624.2 & 32.2 \\
\hline Maternity & 1812 & 79.2 & 1089.7 & 78.4 & 722.3 & 80.3 \\
\hline Pediatrics & 746 & 45.9 & 251.8 & 40.0 & 494.2 & 49.7 \\
\hline Surgery & 1262.8 & 66.8 & 712.8 & 77.7 & 550.0 & 56.5 \\
\hline Total & 4972.1 & 55.3 & 2581.5 & 61.6 & 2390.7 & 49.7 \\
\hline
\end{tabular}

$p<0.001$

Table 2: Consumption by class of antibiotic at the university hospital in Conakry.

\begin{tabular}{|llll|}
\hline ATC class & Consumption in DDD/100 BD & \\
& Conakry university hospital & $\begin{array}{l}\text { Ignace deen } \\
\text { Hospital }\end{array}$ & $\begin{array}{l}\text { Donka } \\
\text { Hospital }\end{array}$ \\
\hline J01A - Tetracyclines & 1.1 & 1.9 & 0.3 \\
\hline J01C - Beta-lactam antibiotics, penicillins & & & \\
\hline Which j01ca - penicillins with extended spectrum & 22.9 & 16.2 & 28.8 \\
\hline Which j01ce - penicillin sensitive to beta-lactams & 0.3 & 0.1 & 0.5 \\
\hline Which j01cf - penicillin resistant to beta-lactams & 0.1 & 0.0 & 0.1 \\
\hline$\quad$ Which j01cr - association of penicillin & 0.9 & 0.7 & 1.1 \\
\hline J01D - Other beta-lactam & & & \\
\hline$\quad$ Which J01DB - (t) $^{\text {st }}$ Generation Cephalosporins & 0.8 & 0.4 & 1.2 \\
\hline$\quad$ Which j01dd - ${ }^{2}$ Generation Cephalosporins & 14.7 & 21.8 & 8.4 \\
\hline J01E - Sulfonamides and trimethoprim & 3.9 & 2.1 & 5.4 \\
\hline J01F -Macrolides & 1.9 & 3.5 & 0.5 \\
\hline J01G - Aminosides & 1.9 & 3.8 & 0.2 \\
\hline J01M - Quinolones & 2.6 & 3.7 & 1.7 \\
\hline J01R + j01X - Associations and other antibacterial & 3.1 & 5.3 & 1.2 \\
\hline Other classes & 1.1 & 2.1 & 0.2 \\
\hline Total & 55.3 & 61.6 & 49.7 \\
\hline
\end{tabular}

The consumption is dominated by the class of extended Spectrum penicillin's (22.9 DDD / 100 BD), followed by the $3^{\text {rd }}$ generation cephalosporin's (14.7 DDD / $\left.100 \mathrm{BD}\right)$. There is a significant difference $(p<0.001)$ between the two national hospitals (Table 2). The median duration of treatment was 3 days; for example, 2 days in Maternity and 5 days in the other wards. $86.1 \%$ of all doses were given parenterally (data not shown).

\section{Knowledge and doctor's perception}

Of a total of 189 prescribers who received the questionnaire, 164 responded with a response rate of $86.8 \%$. Of the 164 respondents, $89(54.3 \%)$ were in the Ignace Deen hospital and $75(45.7 \%)$ at Donka hospital.
There was no significant difference between the two hospitals in the characteristics of prescribers.

The median knowledge score of prescribers, established with a total of 8 , was equal to 5, with a P25 of 4 and P75 of 6 , but no differences between the two national hospitals $(\mathrm{p}=0.865)$ (data not shown).

Prescribers surveyed think in most cases, that selfmedication $(91.5 \%)$, and the fact that the patient did not finish the treatment $(79.3 \%)$, are the main causes for the development of antibiotic resistance. Only $9.76 \%$ cite the large prescription and the high consumption of antibiotics in hospitals (Figure 1). 
Table 3: Composite index for proper use of antibiotics (CIATB).

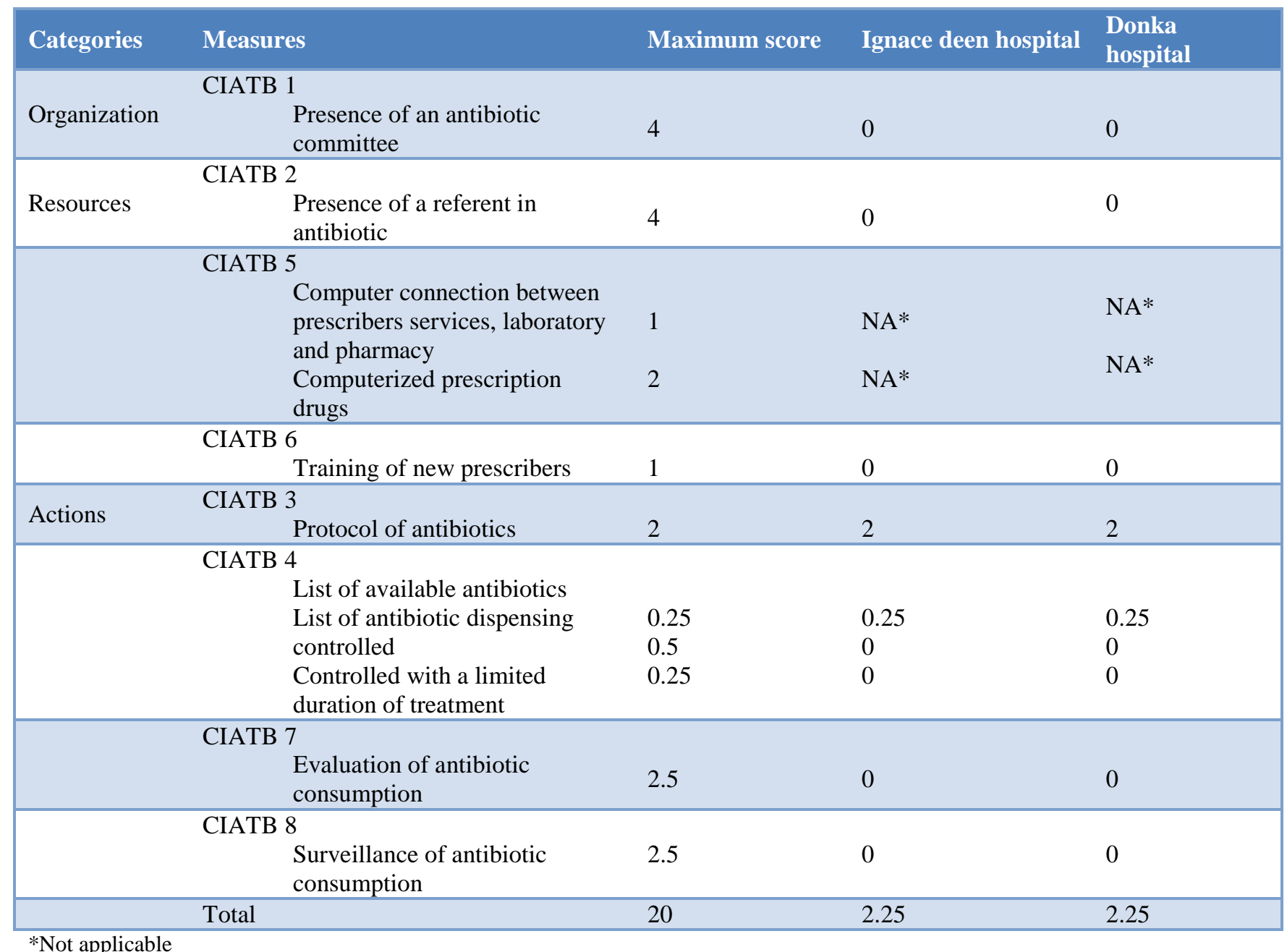

*Not applicable

\section{Evaluation of policies}

The Antibiotic policies evaluated using the CIATB show that the two national hospitals are identical (2.25/20). This score corresponds to the lower category (performance class E) if they were compared to French hospitals (Table 3).

\section{Determinants analysis}

The determinants of antibiotic use were analyzed in two ways. First, we use a regression model analysis of covariance; we analyzed the determinants of consumption in the patient (number of DDD / patient). This reveals that the amount of antibiotics received by a patient is significantly associated with the duration of hospitalization, the site of hospital and the type of service. The age and the gender of the patient when adjusted for the type of ward were no significant (Table 4). We also tested in univariate analysis if consumption of DDD / $100 \mathrm{BD}$ in service was associated to others determinants. We found a non-significant negative correlation $(\mathrm{r}=-0.64)$ with the knowledge score $(\mathrm{p}=$ $0.47)$ and a positive $(\mathrm{r}=0.85)$ and significant correlation $(\mathrm{p}=0.007)$ with patient demand (data not shown).

Table 4: Determinants associated with the consumption of antibiotics in patients.

\begin{tabular}{|ll|l|}
\hline Variables & $\begin{array}{l}\text { Regression } \\
\text { coefficient }\end{array}$ & $\begin{array}{l}\mathbf{p} \\
\text { value }\end{array}$ \\
\hline Ord.Orig. & 3.311 & $<0.001$ \\
\hline Age & 0.007 & 0.52 \\
\hline Sex & 0.576 & 0.12 \\
\hline Number of hospitalization days & 0.285 & $<0.001$ \\
\hline Hospital Donka & -0.593 & $<0.001$ \\
\hline Ward & & \\
Surgery & 2.295 & $<0.001$ \\
Medicine & 0.436 & 0.20 \\
Pediatrics & -1.519 & $<0.001$ \\
\hline Hospital Donka*Ward Surgery & -1.213 & $<0.001$ \\
\hline Hospital Donka*Ward Medicine & 0.309 & 0.25 \\
\hline Hospital Donka*Ward Pediatrics & 0.781 & 0.004 \\
\hline Summary of regression: R $=0.59 ; \mathrm{p}<0.001 ; \mathrm{R}^{2}$ Adjusted $=0.34$
\end{tabular}




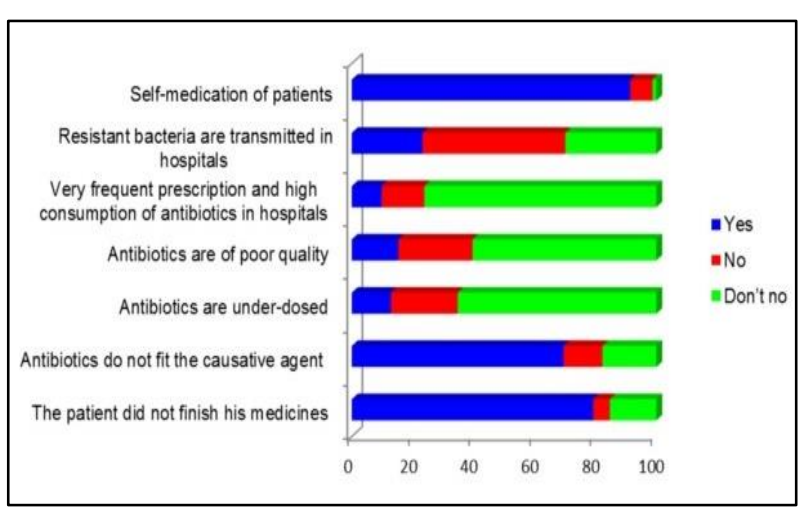

Figure 1: Doctor's perception on the causes of bacterial resistance.

\section{DISCUSSION}

\section{Consumption description}

Our study on the use of antibiotics showed that $79.5 \%$ of hospitalized patients receive at least one antibiotic in the Conakry University Hospital. This rate seems relatively high when compared to European countries like Norway $(16.6 \%),{ }^{18}$ Turkey $(30.6 \%),{ }^{19}$ and even Italy $(45.5 \%),{ }^{20}$ despite this country has one of the highest rates in Europe. However, a similar rate in our study has been reported in China $(77.8 \%),{ }^{21}$ and a greater rate in Nigeria $(96.7 \%) .^{22}$ This difference with European countries could be partly due to the difference in the epidemiology of diseases and the reasons for hospitalization; but also, to the implementation of policies for the rational use of antibiotics.

The total consumption of antibiotics was 55.3 DDD/100 BD. Moreover, this level of consumption of antibiotics in our study is higher than that of European countries. ${ }^{23}$ It is also higher than the results reported in Indonesia. ${ }^{24}$ The paucity of data in the African region on the evaluation of antibiotic consumption by the standards of the WHO (DDD/100 BD) does not allow a comparison with the data from African countries.

Extended-spectrum penicillin's are the most frequently used antibiotics $(41 \%)$ at the University Hospital of Conakry. The third generation of cephalosporin's is the second most consumed large classes $(27 \%)$. This rate rises to $43 \%$ in the Maternity ward of Ignace Deen, when the use of the $3^{\text {rd }}$ generation of cephalosporin's represents only $4 \%$ of consumption in the maternity of Donka. This difference of practice needs further analysis.

The median duration of antibiotic treatment in the University Hospital of Conakry was 3 days, with an extreme at 20 days. A meta-analysis of five randomized trials totaling 2800 patients showed that the treatment for below 7 days for mild to moderate pneumonia was as effective as treatment for above 7 days with the same antibiotic at the same dosage. ${ }^{25}$ Optimizing the duration of the antibiotic therapy is an important measure to reduce the side effects, prevent the resistance and reduce the processing costs. The knowledge of the optimal duration of the therapy for common infections, responsible for the vast majority of antibiotic consumption, would be particularly useful. ${ }^{26}$

Parenteral route was chosen in $86.1 \%$ of prescriptions with significantly more intravenous antibiotics used in the Donka Hospital $(88.3 \%)$ than in the Ignace Deen Hospital (84.6\%). This rate, despite being high, is superimposed on a reported rate $(83.7 \%)$ in France. $^{27}$ Although parenteral use often depends on the clinical condition of the patient, we must remember that using injections when oral formulations are as effective is an irrational use of drugs because the cost of injections is always higher than the oral therapy. Moreover; it increases the risk of blood-borne diseases such as hepatitis and HIV / AIDS. ${ }^{28}$

Finally, it should be noted that our study also revealed that no susceptibility testing was performed for the 953 patients included. Therefore, we can conclude that the antibiotics use in the Conakry University Hospital is essentially empirical and there are probably few data on local epidemiology to help physicians in the clinical decisions.

The analysis by a regression model shows that the hospital site (greater amount if the patient is hospitalized in Ignace Deen), service (more antibiotics in surgery and fewer antibiotics in Paediatrics), and length of stay was associated with higher antibiotic consumption (Table 4). Age and sex of the patients were not determinant in the use of antibiotics. These results are consistent with various literature data. Indeed, a study in 77 French hospitals reported that the duration of stay in the medical and surgical services was one of the predictors of change in antibiotic consumption. ${ }^{3}$ In a thesis in Indonesia; Hadi has reported that, compared to the patients treated in the department of internal medicine, the probability of having a prescription of an antibiotic in the department of surgery was $4.9,4.5$ for pediatrics and gynecology and 3.4 for Obstetrics. ${ }^{24}$

\section{Knowledge and doctor's perception}

The median score of knowledge about the antibiotics is similar to the scores reported in the Democratic Republic of Congo. ${ }^{16}$ It is often assumed that the differences in the practices of the prescription of health care providers are inextricably linked to a variable level of training and knowledge. ${ }^{29,30}$ However, there is a little evidence to support this hypothesis. ${ }^{31}$ It is interesting to note that our study shows the influence of the knowledge on prescribing practice. The analysis of the determinants of consumption by wards showed a negative, but not significant, correlation $(r=-0.64)$, between the knowledge score and the consumption expressed in DDD/100 BD ( $\mathrm{p}=0.47)$. 
In our study, the perception of the causes of resistance shows that prescribers are more likely to make patients responsible for the development of drug resistance (selfmedication, incomplete cure). Few believe that the prescription and the high consumption of antibiotics in hospital alone are one of the most important causes of drug resistance. This could limit the impact of measures to reduce the emergence of resistance; because according to the social cognitive theory, the behavior of an individual is conditioned in part by the perception that the individual has about the consequences of his actions. ${ }^{32}$

\section{Evaluation of policies}

The CIATB reflects the level of commitment to the health facility, in an optimization of the effectiveness of the antibiotic treatment strategy. ${ }^{17}$ The CIATB obtained at Conakry shows a lack of any measure aimed at the rational use of antibiotics. Some studies report that political actions (antibiotic's policies) in hospitals could influence the use of antibiotics in a specific organization. In their survey of 977 French hospitals, Amadeo et al. found a positive correlation between antibiotic consumption expressed in defined daily doses (DDD) and CIATB. $^{33}$

However, our study did not allow us to compare both hospital antibiotic policies on consumption since CIATB score was the same in both hospitals. However, the analysis of data collected shows that these two hospitals are different in terms of consumption of antibiotics. Other factors could explain these differences in practices, such as case-mix of hospitals or quality of services.

\section{CONCLUSION}

A potential limitation of the study can be found in the limited accuracy of measuring the amount of antibiotics given by the retrospective review of medical records, the absence of coupling consumption data with case-mix and the self-selection bias in the cross sectional component. However, few data on antibiotics consumption in developing countries are available. The results of this study could be useful for managers, physicians, pharmacists of both hospitals as executives of the Ministry of Health of Republic of Guinea; but also, by extrapolation, for other surrounding countries. Measuring, or defining indicators, is the first step of an intervention plan. This study, by using the standardized method proposed by the WHO for measuring the consumption of antibiotics, allows the comparison with other countries in the world.

In the end, based on the results of our study, it appears that a lot of antibiotics are consumed in the Conakry University Hospital and that consumption is influenced by the hospital site, the medical discipline and the length of stay. We also observed the absence of a policy of the rational use of antibiotics. That illustrates the urgent need for implementation of an Antimicrobial Stewardship Action.

\section{ACKNOWLEDGEMENTS}

Authors want to thank Nadia Dardenne for her advice, Amara Diawara for his help in the data collecting and all medical doctors at Conakry University Hospitals who have participated in this study.

Funding: No funding sources Conflict of interest: None declared

Ethical approval: The study was approved by the Institutional Ethics Committee

\section{REFERENCES}

1. WHO. Promoting rational use of medicines: core components. WHO policy perspectives on medicines. 2002:005. Available at: http://apps.who.int/medicinedocs/en/d/Jh3011e/. Accessed on 06 April 2016.

2. WHO. The pursuit of responsible use of medicines: sharing and learning from country experiences, 2012. Available at: http://www.who.int/medicines/areas/rational_use/en /. Accessed on 06 April 2016.

3. Amadeo B, Dumartin C, Robinson P, Venier A, Parneix P, Gachie J, et al. Easily available adjustment criteria for the comparison of antibiotic consumption in a hospital setting: experience in France. Clin Microbiol Infect. 2010;16(6):735-41.

4. Patry I, Leroy J, Henon T, Talon D, Hoen B, Bertrand X. Evaluation of antibiotic prescription in a French university hospital. Medecine et maladies infectieuses. 2008;38(7):378-82.

5. Bassetti M, Di Biagio A, Rebesco B, Amalfitano M, Topal J, Bassetti D. The effect of formulary restriction in the use of antibiotics in an Italian hospital. Eur J Clin Pharmacol. 2001;57(6-7):52934.

6. Monnet DL, Archibald LK, Phillips L, Tenover FC, McGowan Jr JE, Gaynes RP. Antimicrobial use and resistance in eight US hospitals: complexities of analysis and modelling. Infect Control Hosp Epidemiol. 1998:388-94.

7. Goossens H, Ferech M, Stichele RV, Elseviers M. Outpatient antibiotic use in europe and association with resistance: a cross-national database study. The Lancet. 2005;365(9459):579-87.

8. Hsueh PR, Chen WH, Luh KT. Relationships between antimicrobial use and antimicrobial resistance in Gram-negative bacteria causing nosocomial infections from 1991-2003 at a university hospital in Taiwan. Int $\mathrm{J}$ Antimicrob Agents. 2005;26(6):463-72.

9. Goldmann DA, Huskins WC. Control of nosocomial antimicrobial-resistant bacteria: a strategic priority for hospitals worldwide. Clin Infect Dis. 1997;24(Supplement 1):S139-S45. 
10. Conseil du médicament Quebec. Cadre de référence relatif à l'usage optimal des anti-infectieux et au suivi de l'utilisation de ces médicaments en milieu hospitalier, 2008. Available at: http://www.inesss.qc.ca/fileadmin/doc/CDM/Etudes /CdM-Cadre-antiinfectueux-200810.pdf. Accessed on 06 April 2016.

11. Hulscher ME, van der Meer JW, Grol RP. Antibiotic use: how to improve it? Int J Med Microbiol. 2010;300(6):351-6.

12. Evirgen O, Onlen Y, Ertan O. The intensity of antibiotic usage in the university hospital and the investigation of an inappropriate use of antibiotics. Bratislavske lekarske listy. 2010;112(10):595-8.

13. WHO collaborating centre for drugs statistics methodology: Use of ATC/DDD, 2011. Available at: http://www.whocc.no/use_of_atc_ddd/. Accessed on 06 April 2016.

14. Palcevski V, Morovic M, Palcevski G. Antibiotic utilization at the university hospital after introducing an antibiotic policy. Eur J Clin Pharmacol. 2000;56(1):97-101.

15. Kra O, Ehui E, Ouattara B, Tanon A, Bissagnene E, Kadio A. Utilisation des antibiotiques dans les services d'urgence medicale des CHU d'abidjan (cote d'ivoire). Médecine d'Afrique noire. 2006;53(1):55-9.

16. Thriemer K, Katuala Y, Batoko B, Alworonga JP, Devlieger $\mathrm{H}$, Geet $\mathrm{CV}$, et al. Antibiotic prescribing in DR Congo: a knowledge, attitude and practice survey among medical doctors and students. PloS one. 2013;8(2):e55495.

17. Ministère des Affaires Sociales. De la Santé et des Droits des femmes, France. Indicateur composite de bon usage des antibiotiques, 2012. Available at: http://social sante.gouv.fr/fichiers/bo/2012/1208/ste_20120008_0100_0042.pdf. Accessed on 13 April 2016.

18. Berild D, Ringertz SH, Lelek M. Appropriate antibiotic use according to diagnoses and bacteriological findings: report of 12 pointprevalence studies on antibiotic use in a university hospital. Scand J Infect Dis. 2002;34(1):56-60.

19. Usluer G, Ozgunes I, Leblebicioglu H. A multicentre point-prevalence study: antimicrobial prescription frequencies in hospitalized patients in Turkey. Annals of clinical microbiology and antimicrobials. 2005;4(1):16.

20. Porretta A, Giuliani L, Vegni F, Larosa M, Privitera G. Prevalence and patterns of antibiotic prescribing in Italian hospitals. Infection. 2003;31:16-21.

21. Hu S, Liu X, Peng Y. Assessment of antibiotic prescription in hospitalised patients at a Chinese university hospital. J Infect. 2003;46(3):161-3.

22. Chukwuani C, Onifade M, Sumonu K. Survey of drug use practices and antibiotic prescribing pattern at a general hospital in Nigeria. Pharmacy world and science. 2002;24(5):188-95.
23. ECDC/EMEA joint working group. ECDC/ EMEA joint technical report: the bacterial challenge: time to react. Stockholm: european centre for disease prevention and control, 2009. Available at: http://www.ecdc.europa.eu/en/publications/Publicati ons/0909_TER_The_Bacterial_Challenge_Time_to _React.pdf. Accessed on 13 April 2016.

24. Hadi, U, Keuter M, Van Asten H, Den Broek PV. On behalf of the study group 'antimicrobial resistance in indonesia: prevalence and prevention.' AMRIN. 2008;13:888-99.

25. Li JZ, Winston LG, Moore DH, Bent S. Efficacy of short-course antibiotic regimens for communityacquired pneumonia: a meta-analysis. Am J Med. 2007;120(9):783-90

26. Volluz SD. Quelle est la durée optimale de l'antibiothérapie pour les infections fréquentes? Maladies infectieuses. 2010;266(36):1901-5.

27. Mettler J, Simcock M, Sendi P, Widmer AF, Bingisser R, Battegay M, et al. Empirical use of antibiotics and adjustment of empirical antibiotic therapies in a university hospital: a prospective observational study. BMC infectious diseases. 2007;7(1):21.

28. Grand AL, Hogerzeil HV, Haaijer-Ruskamp FM. Intervention research in rational use of drugs: a review. Health policy and planning. 1999;14(2):89102.

29. Bosu W, Ofori-Adjei D. Survey of antibiotic prescribing pattern in government health facilities of the wassa west district of Ghana. East African medical journal. 1997;74(3):138-42.

30. Okeke IN, Lamikanra A, Edelman R. Socioeconomic and behavioral factors leading to acquired bacterial resistance to antibiotics in developing countries. Emerging infectious diseases. 1999;5(1):18.

31. Guyon AB, Barman A, Ahmed J, Ahmed A, Alam M. A baseline survey on use of drugs at the primary health care level in Bangladesh. Bulletin of the World Health Organization. 1994;72(2):265-72.

32. Godin G, Bélanger AG, Eccles M, Grimshaw J. Healthcare professionals' intentions and behaviours: A systematic review of studies based on social cognitive theories. Implement Sci. 2008;3(36):1-12.

33. Amadeo B, Dumartin C, Parneix P, Fourrier-Réglat A, Rogues AM. Relationship between antibiotic consumption and antibiotic policy: an adjusted analysis in the french healthcare system. J Antimicrob Chemother. 2010:dkq456.

Cite this article as: Keita M, Traore F, Camara ME, Camara AY, Sandouno SD, Van Hees T. The use of antibiotics in the university hospitals of Conakry: evaluation of the consumption and the analysis of determinants. Int J Community Med Public Health 2016;3:1547-53. 